\title{
Current status of faculty development in under graduate medical education of Bangladesh
}

\author{
Dr. Shamima Rahman ${ }^{1}$, Prof. Dr. Soofia Khatoon², Dr. Mossammat Nigar Sultana ${ }^{3}$, Dr. Farhana Noman", \\ Dr. Sayed Golam Samdani ${ }^{5}$
}

\begin{abstract}
This descriptive cross sectional study was carried out to determine the current status of faculty development in undergraduate medical education of Bangladesh. This study was carried out in eight (four Government and four Non- Government) medical colleges in Bangladesh over a period from July 2015 to June 2016.

The present study had a semi-structured self-administered questionnaire for individual teacher. Total 181 teachers responded to the questionnaire. $56 \%$ of teachers said that faculty development activities were regularly conducted. About duration of faculty development activity $74 \%$ of teachers said it was $1-3$ days duration. $42 \%$ of the teachers said faculty development activity conducted once in a week and 39\% said occasional conduction of faculty development activity in their institute

About the type of faculty development activity clinical meeting was commonest (65\%), related to medical education (48\%) and related to research (53\%). About the topics of medical education related activities were teaching methodology (46\%), assessment (32\%). Research related activities were journal club (91\%) and research methodology (67\%). Faculty development activity was conducted through teachers association (53\%) and medical education unit (50\%).

In conclusion some parts of FD activity are present in most of the colleges like clinical meeting, few medical education related session, and research related activity. For upgrading of medical education faculty development programme should be conducted regularly, monitoring of present programme and development of qualified resource person should be ensured.
\end{abstract}

Key Words: Faculty development, current status, undergraduate medical education

\section{Introduction}

Change is the way of life. We live in present time. Future calls for fundamental changes and new ways. These statements also true for medical education. There is also a need for creation new strategy to prepare the future healthcare professionals. This requires adoption of new curricula, novel pedagogies and innovative forms of faculty members ${ }^{1}$.

In many ways, faculty development is a planned program to prepare institutions and faculty members for their academic roles, including teaching, research, administration, writing and career management ${ }^{2}$.To help faculty members fulfill

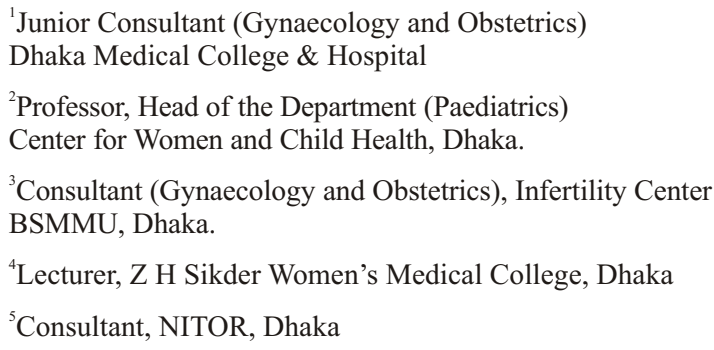

Address of correspondence: Dr. Shamima Rahman Junior Consultant (Gynaecology and Obstetrics)

Dhaka Medical College \& Hospital

Email:jamana2502@yahoo.com their multiple roles, a variety of faculty development programs and activities have been designed and implemented. These activities include workshops and seminars, short courses and site visits, fellowships and other longitudinal programs ${ }^{3,4}$.

\section{Background}

The World Health Organization (WHO), has been actively advocating the reform of medical education to meet the changing needs of the current and future society at both global and regional levels. A reorientation of medical education movement started in the early 1980s in Bangladesh. The Centre for Medical Education (CME) was set up at Dhaka in 1983 by an UNDP-funded project in the country. One of the main objectives of the CME is to train medical teachers on basic principle of teaching methodology and assessment as a part of faculty development programme ${ }^{5}$.

Centre for Medical Education, Dhaka has been conducting workshops, seminar and conference to train up medical teachers and allied health professionals on very important issues related to our medical and dental curriculum since its establishment (1993). Centre for Medical Education conducts training on educational science and teaching methodology, quality assurance in medical education, educational research methodology and biostatistics, problem based learning, Teaching health ethics, instructional

Bangladesh Journal of Medical Education 2017;8(2):2-8. (C) 2017 Rahman et al., publisher and licensee Association for Medical Education. This is an Open Access article which permits unrestricted non-commercial use, provided the original work is properly cited. 
material development, assessment and evaluation, curriculum development, instructor and programme evaluation, and educational management. Due to shortage of manpower and fund CME can train up only 200- 400 (Annual reports of CME) teachers in each year. But large number of medical and allied health professional teachers still remained untrained related their faculty roles. Centre for Medical Education evolved as a future postgraduate training institute in 2004 with introduction of two years Masters in Medical Education (MMEd) course for the medical and dental teacher.

\section{Rationale}

Conventional role of the medical teachers as information provider has changed in present time. Now the academic roles and responsibility expanded to learning facilitator, resource material producer, curriculum and course planner, student assessor, mentor and program evaluator. This is obvious challenge for medical teachers. So teachers need to take part in faculty development program which prepare them to face the challenge.

In consideration of above mentioned facts, the researcher in this study has tried to find out the current status of faculty development practiced in undergraduate medical education in Bangladesh, its strength, weakness. Findings and recommendations of the study may suggest some modification and strengthening of present faculty development program.

\section{Methodology}

This was a descriptive type of cross- sectional study, carried out from July 2015 to June 2016. This study was conducted in the eight medical colleges of Bangladesh, four government (two from Dhaka city, two outside Dhaka city and four non-government institutes (two from Dhaka city two outside Dhaka city ).Study population of this study were teachers of medical colleges. Sampling unit was each teacher medical college. Teachers were included in this study from lecturer to Professor of all disciplines of the selected medical colleges.

Total One hundred eighty one (181) teachers were enrolled from eleven major department of eight medical colleges as per under graduate medical curriculum.

Sampling was done by convenience sampling. Data collection instrument was a semi- structured and selfadministered questionnaire for teachers of medical colleges. The data collection instruments were pretested upon the twenty teachers of Dhaka Medical College. The Principals of the medical colleges was approached through a forwarding letters from director CME was describing the purpose of the study \& requesting him for necessary permission to conduct the study. The researcher had visited the selected medical colleges personally. She introduced herself to the concerned authority of the medical college hospital and she was seeking permission to conduct the study. The researcher introduced herself to the teachers and was briefing them about the purpose of the study and the questionnaire. She had distributed questionnaire to teacher after doubts are clarified by the researcher. Questionnaire was filled up in presence of researcher. Teachers returned the filled up questionnaire to the researcher. Open question were edited after collection and coded manually. Qualitative data checked \& edited .Then responses were listed according to theme, frequency were tally marked. Tallies added and data presented in the form of table. Some part of qualitative data will be presented in narrative form. Quantitative part of data checked \& edited after collection. Then coded manually, processed \& analyzed by using SPSS software package according to the objectives. For each variable frequency was calculated. Data presented in the form of table \& graphs. Necessary description had given to show the findings Written permission was taken from the principal of the respective medical colleges prior to data collection. Participation by the respondent in the study were totally voluntary. Anonymity of the respondents was maintained. Confidentiality of the information was ensured. Name of college and teacher was not disclosed. Finding of the study was used only for research purpose.

\section{Results}

This descriptive type of cross sectional study was carried out to determine the current status and future perspective of faculty development in undergraduate medical education in Bangladesh. This study was carried out in eight (Four Governments and Four Governments) medical colleges in Bangladesh over the period July 2015 to June 2016.

Total 181 teachers were introduced and they filled up semistructured self- administered questionnaires were filled up by teachers. Results of this were organized of different tables and figures.

Current status of faculty development from teachers by semi-structured self-administered questionnaire and qualitative analysis of open question.

All teachers (100\%) agreed that professional improvement was necessary for their job.

Table 1: Distribution of teacher by their opinion about the extent of necessity of professional improvement $(\mathrm{n}=180)$

\begin{tabular}{|l|c|c|}
\hline $\begin{array}{l}\text { Extent of necessity of professional } \\
\text { improvement }\end{array}$ & Frequency & Percent \\
\hline Highly essential & 88 & 48.9 \\
\hline Moderately essential & 89 & 49.4 \\
\hline Minimally essential & 3 & 1.7 \\
\hline Total & 180 & 100.0 \\
\hline
\end{tabular}

Table 1 showed that $48.9 \%$ medical teachers of selected medical colleges said that professional improvement is highly essential, almost equally (49.4\%) said that it is moderately essential. 
Table 2: Distribution of teachers by their opinion about the nature of regularity of faculty development (FD) activity conducted in their institute $(n=181)$

\begin{tabular}{|l|c|c|}
\hline $\begin{array}{l}\text { Regularity of faculty development } \\
\text { activity }\end{array}$ & Frequency & Percent \\
\hline Regularly conducted & 102 & 56.4 \\
\hline Irregularly conducted & 864 & 35.4 \\
\hline Not conducted & 315 & 8.3 \\
\hline Total & 181 & 100.0 \\
\hline
\end{tabular}

Table 2 showed $56.4 \%$ of the medical teachers opined that faculty development activity conducted in their institute regularly.

Table 3: Distribution of teachers by their opinion about the authority who was conducting faculty development (FD) activity conducted in their institute last year $(n=181)$

\begin{tabular}{|l|c|c|}
\hline Authority conducting FD activity & Frequency & Percent \\
\hline Teachers association & 96 & 53.03 \\
\hline Medical education unit & 90 & 49.72 \\
\hline Total & 186 & 102.75 \\
\hline
\end{tabular}

* Responses are more than $100 \%$ due to multiple responses.

Table 3 showed the distribution of teacher's by their opinion about authority conducting faculty development activity in their institute last year. 53\% teachers said that research related faculty development activity conducted by teachers association and $49.72 \%$ of teachers said that it was conducted by medical education unit last year.

Table 4: Distribution of teachers by their opinion about the frequency of faculty development activity conducted in their institute $(\mathrm{n}=166)$

\begin{tabular}{|l|c|c|}
\hline $\begin{array}{l}\text { Frequency of faculty development } \\
\text { activity }\end{array}$ & Frequency & Percent \\
\hline Once in a week & 69 & 41.6 \\
\hline Once in a fortnight & 24 & 14.6 \\
\hline Once in month & 9 & 5.4 \\
\hline Occasionally & 64 & 38.6 \\
\hline Total & 166 & 100 \\
\hline
\end{tabular}

Table 4 showed $42 \%$ teachers said that faculty development activity that had conducted once in week, about $15 \%$ once in a fortnight and $38.6 \%$ of teachers said at faculty development activity had occasionally conducted in their institute
Table 5: Distribution of teachers by their opinion about the types of faculty development activity conducted in their institute $(\mathrm{n}=181)$

\begin{tabular}{|l|c|c|}
\hline $\begin{array}{l}\text { Types faculty development activity } \\
\text { conducted in medical colleges }\end{array}$ & Frequency & Percent \\
\hline Clinical meeting & 116 & 65.2 \\
\hline Topics related to research & 96 & 53 \\
\hline Topics related to medical education & 87 & 48.1 \\
\hline Total & 299 & 165.2 \\
\hline
\end{tabular}

*Responses are more than $100 \%$ due to multiple responses.

Table 5 showed $65 \%(116)$ teachers said that clinical meeting, $48 \%(87)$ teachers said that topics related to medical education, 53\% (96) teachers said that research related faculty development activity had conducted in their institute.

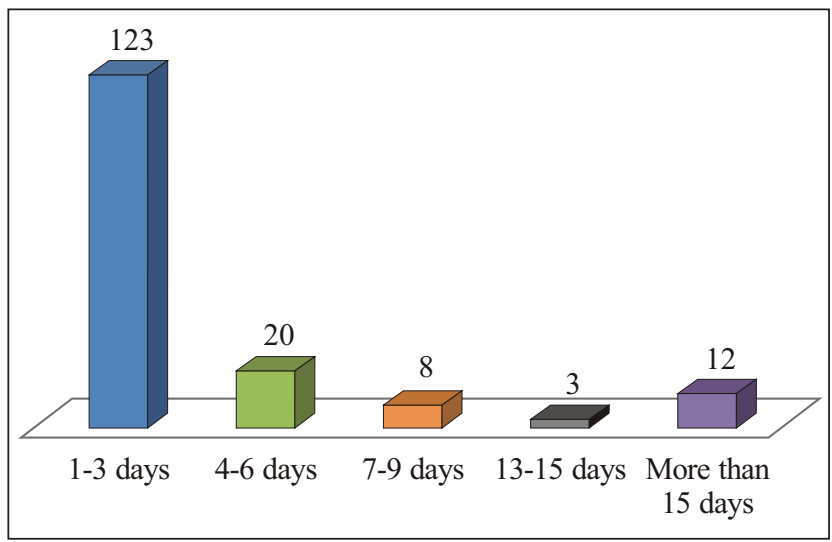

Figure 1: Distribution of teachers by their opinion about duration of faculty development activity conducted in their institutes $(\mathrm{n}=166)$

Figure 4 showed $74 \%$ teachers commented that faculty development activity that were of 1-3 days duration, $12 \%$ of 4-6 days duration.

Table 6: Distribution of teachers by their opinion about faculty development activity related to medical education conducted in their institute $(\mathrm{n}=87)$

\begin{tabular}{|l|c|c|}
\hline $\begin{array}{l}\text { Faculty development activity } \\
\text { related to medical education }\end{array}$ & Frequency & Percent \\
\hline Teaching methodology & 68 & 78.2 \\
\hline Assessment & 43 & 49.4 \\
\hline Instructional material development & 35 & 40.2 \\
\hline Curriculum Development & 13 & 14.9 \\
\hline $\begin{array}{l}\text { Programme evaluation \& faculty } \\
\text { development }\end{array}$ & 8 & 9.2 \\
\hline Total & 167 & 191.95 \\
\hline
\end{tabular}

*Responses are more than $100 \%$ due to multiple responses

Table 6 showed $78.2 \%$ of the teachers said that teaching methodology, $49.4 \%$ of the teachers said that assessment. 
Table 7: Distribution of teachers by their opinion about the types of research related faculty development activity conducted in their institutes $(n=96)$

\begin{tabular}{|l|c|c|}
\hline Types research related activity & Frequency & Percent \\
\hline Journal Club & 87 & 90.62 \\
\hline Research Methodology & 64 & 66.7 \\
\hline Total & 151 & 157.3 \\
\hline
\end{tabular}

*Responses are more than $100 \%$ due to multiple responses

Table 7 showed $90.6 \%$ of the teachers said that journal and $67.7 \%$ said that research methodology related FD conducted in their institutes.

\section{Discussion}

This descriptive cross sectional study was carried out four government and four nongovernment medical colleges in and outside of Dhaka city. This study was done to find out the current status of faculty development activity present on undergraduate medical education, the barriers for improvement of faculty and also tried to find out the suggested responsibilities of concerned authorities according to teachers opinion for further improvement of faculty.

\section{Current status of faculty development: Teachers opinion}

\section{Necessity of faculty development}

The present study findings revealed that all of teachers agreed further professional improvement was necessary for their job. $49 \%$ teachers said that professional improvement were moderately essential and another half (48.61\%) of medical teachers agreed that professional improvement was highly essential for them. (Table 1). Steinert ${ }^{6}$ (2010) stated that in 2006, as a part of the BEME ( Best Evidence in Medical Education) collaboration, an international group of medical education systematically reviewed the faculty development literature to ascertain the impact of formal initiatives on teaching improvement. The results of this review indicated overall satisfaction with faculty development programmes.

\section{Regularity, topics, and frequency of faculty development activity}

The present study findings revealed that more than half of the medical teachers( $56.4 \%$ ) said that faculty development activity conducted regularly in their institute, about one third $(35.4 \%)$ of the teachers said that irregular conduction of faculty development activity (Table 2). The present study revealed that $42 \%$ teachers said faculty development activity that had conducted once in week, about $15 \%$ once in a fortnight and $38.6 \%$ of teachers said at faculty development activity had occasionally conducted in their institute (Table- 4). Mukhtar ${ }^{7}$ (2010) stated that there were 65 medical colleges (public and private) recognized by Pakistan Medical and Dental Council. Of these, responses were received from 45 teaching institutions in the country. Out of a total of 45 medical colleges who responded, 37
$(82 \%)$ indicated that they had a faculty development programme. Clark (2004) stated that twenty-six percent of the 277 respondents reported that they had no FD activities in teaching skills, 35\% reported occasional, and 39\% (N= 108) reported ongoing activities.

\section{Department conducting FD}

The present study revealed that $53 \%$ of teachers said that research related faculty development activity conducted by teachers association and 50\%of teachers said that FD conducted by medical education unit in their medical colleges last year (Table 3). Srinivas ${ }^{8}$ (2009) stated in his study that MEUs, particularly those in recently established colleges should become functional and engaged in activities like faculty development, curricular innovations, student assessment and educational research.

\section{Types of faculty development programme}

In this study among faculty development activity majority $(65 \%)$ were clinical meeting on different subject, nearly half $(48 \%)$ of topics were about medical education and more than half $(53 \%)$ were related to research (Table 5). From the study researcher noticed that clinical meeting was the most common format of faculty development activity. It may be due to clinical case discussion is interesting for all. In addition no need of special expertise.

\section{Duration of faculty development activity}

About the duration of FD programme in their college this study revealed that majority of teachers (74\%) said that faculty development activity was of 1-3 days duration, 12\% said it was of 4-6 days duration (Figure 1). Clark ${ }^{3}$ (2004) also stated that faculty development activities were most likely to be offered as a half-day workshop (80\% of ongoing programs). Forty percent of hospitals utilized courses of $>0.5$ to 2 days, $16 \%$ used courses of $>2$ to 7 days, $16 \%$ courses of $>7$ days to 1 month, and $22 \%$ had programs of $>1$ month duration.

\section{Topics of Medical Education}

$45.86 \%$ of teachers said that teaching methodology, one third $(32 \%)$ of teachers said that assessment, another one third $(25 \%)$ about instructional material development, about $13 \%$ about curriculum development were the topics of medical education related activity (Table 6) Mukhtar ${ }^{7}$ (2010) stated that the popular topics for training included communication skills $84 \%$ and teaching skills $81 \%$, followed equally by both curriculum development and research methodology $78 \%$. Whereas stress management was the topic addressed by $40 \%$ institutes. The present study differ from that of Mukhter,s that teaching methodology study was the most commonly conducted session in present study whereas communication skills in Mukhter, s study.

\section{Topics of research related activity}

The present study revealed that among research related faculty development activity $48 \%$ of teachers said that journal club and about one third were about research

Bangladesh Journal of Medical Education 2017;8(2):2-8. 
that journal club conduction were prevalent than research methodology in case of research related activity. It might be happened because any doctor who read a particular article can conduct journal presentation in journal club. But a session of research methodology needs expert and knowledgeable faculty.

\section{Conclusions}

This study was conducted to find out the present status of faculty development in undergraduate medical education of Bangladesh. After analyzing the different findings of present study it is clear that all teachers agreed about the necessity of faculty development. Majority of teachers considered it highly or moderately beneficial. In spite of its usefulness it was conducted regularly only in half of the institute. Nearly half of the institute faculty development activity was occasional or absent.

Supervision of faculty development programme by the higher authority should be strengthen. The highest authority of ministry of Health and Family planning should make outlines for teacher evaluation, foreign training for sustainable faculty development.

\section{References}

1. Whitcomb, M.. The medical school's faculty is its most important asset, Acad

Med. 2003; 78(2): 117118.

2. Bland, C.J., Schmitz, C.C., Stritter, F.T., Henry, R.C. \& Aluise, J.J. Successful Faculty in Academic Medicine. 1990; (New York, Springer Publishing).
3. Clark, JM., Houston, TK., Kolodner K, Branch WT, Levine RB, Kern DE. National survey of faculty development in departments of medicine of U.S. teaching hospitals. J Gen Int Med. 2004; 19:205214.

4. Skeff, K.M., Stratos, G.A.and Mygdal, W.. Faculty development a resource for clinical teachers. J Gen Inter Med. 1997 apr ;12, suppl2: 56-63.

5. Majumder MAA. Medical education in Bangladesh past successes, future challenges. Bangladesh Medical Journal. 2003; 32: 37-39.

6. Steinert ,Y., Mann, K., Centeno, A., Dolmans, D., Spencer, J., Gelula, M., Prideaux, D. A systematic review of faculty development initiatives designed to improve teaching effectiveness in medical education: BEME Guide No. 8, Med Teach. 2006; 28(6) : 497526.

7. Mukhtar, F., Chaudhury, A.M.. Faculty development in medical institution: Where do we stand in Pakistan?, J Ayub Med Coll Abbottabad. 2010; 22(3), 210-213.

8. Srinivas D.K.,B.V.Adkoli B. V. Faculty Development in Medical Education in India:

The Need of The Day 2009. Al Ameen Charitable Fund Trust, Bangalore Areview article. Al Ameen J Med Sci. 2009; $2:(1): 6-13$

Bangladesh Journal of Medical Education 2017;8(2):2-8. 